Case Report:

\title{
Transradial Neurointerventional Approach to Basilar Tip crossmark Aneurysm: Case Report and Technical Note
}

\author{
Mohammad Ghorbani ${ }^{1}$, Ebrahim Hejazian ${ }^{1 *}$
}

1. Division of Vascular and Endovascular Neurosurgery, Firoozgar Hospital, Iran University of Medical Sciences, Tehran, Iran

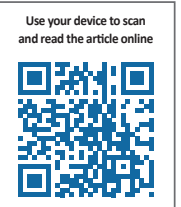

Citation: Ghorbani M, Hejazian E. Transradial Neurointerventional Approach to Basilar Tip Aneurysm: Case Report and Technical Note. Iran J Neurosurg. 2017; 3(3):119-123. https://doi.org/10.29252/IRJNS.3.3.119

: https://doi.org/10.29252/IRJNS.3.3.119

Article info:

Received: 02 August 2017

Last Revised: 21 August 2017

Accepted: 03 September 2017
Keywords:

Transradial, Angiography,

Cerebral, Aneurysm

\begin{abstract}
Cerebral angiography through transfemoral approach is preferred in most of the situations though in cardiovascular surgery transradial angiography is accounted as the superior standard. The present study aimed at presenting our early experience of transradial approach to cerebral angiography and intervention of a patient with basilar tip aneurysm that had inappropriate vasculature to perform routine transfemoral approach. The patient was a 65 year-old man with a large basilar tip aneurysm that was candidate for endosacular coiling through transfemoral route. But due to very tortuous iliac artery, aortic arch and its branches, navigation transfemorraly via both vertebral arteries was impossible. Therefore we decided to do the procedure through right transarterial route. The procedure was started by doing Allen's test to confirm good perfusion of right hand by collateral arteries. After that cerebral angiography and neurointervention was done transradially without any complication. As a result, although a transradial approach is not a routine way for cerebral angiography and intervention, it can be used safely as an alternative way in specific cases.
\end{abstract}

\section{Introduction}

erebral angiography remains the gold standard method for cerebrovascular diseases. The femoral artery is the most common puncture site used for cerebral angiography. However, a transfemoral approach is not possible in all patients, and there are several limitations to this approach. Majority of studies have discussed the advantages of transradial approach since patients find it comfortable and economi- cally advantageous [1-7]. Today, there is no doubt that a huge number of interventional cardiologists prefer transradial angiography. Yet, some doubt it due to some cases of futile application [5, 8-12]. In this paper we present our first case of transradial approach for cerebral angiography and intervention for large basilar tip aneurysm.

\section{Methods \& Materials/Patients}

A 65-year old man with headache referred to our center. He was conscious and had a normal neurologic

* Corresponding Author:

Ebrahim Hejazian, MD

Address: Division of Vascular and Endovascular Neurosurgery, Firoozgar Hospital, Iran University of Medical Sciences, Tehran, Iran

Tel: +98 (911) 32199592

E-mail: sehbums@yahoo.com 
examination, without any concomitant disease. In brain CT (Computed Tomography) scan, a round lesion was found in prepontine cistern without evidence of $\mathrm{SAH}$ (subarachnoid hemorrhage). In cerebral angiography, a large saccular basilar tip aneurysm was found with superior orientation. We decided to treat him by endovascular coiling by routine transfemoral approach. After general anesthesia and during the navigation of aortic arch, we observed very tortuous of iliofemoral, aortic arch and both vertebral arteries that deploying guiding catheter and microcatheter were impossible. Therefore, we changed the approach to the right radial artery. At first we checked radial and ulnar arteries pulsations with Allen's test and confirmed the good collateral perfusion of the hand and safety of radial artery access. The wrist of our patient was extended on a small roll in 30 degree abducted position of the hand. After preparation and draping, the radial artery was punctured at the maximum point of pulsation using. A 20-gauge needle with Seldinger technique by $5 \mathrm{~F}$ radial sheath. After injection of a cocktail solution [comprising a mixture of heparin $(5,000 \mathrm{IU} / \mathrm{mL})$, verapamil $(2.0 \mathrm{mg})$, nitroglycerine (200 $\mu \mathrm{g} / \mathrm{mL} ; 0.25 \mathrm{~mL})]$ to prevent radial artery spasm and thrombosis, we started transradial, transaxillary, transsubclavian and transvertebral artery approach (Figures 1, 2 and 3). A 5-F BER guiding catheter with a 0.035-inch hydrophilic Guidewire was used for the procedure. After inserting the microcatheter in the aneurysm sac in the proper position, coiling was done and the embolization completed (Figure 4).
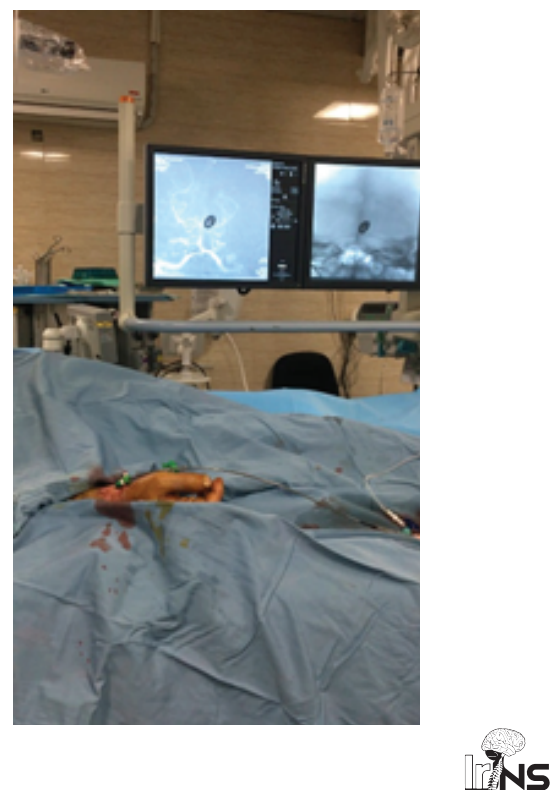

Figure 1. Right Radial Artery Access and Image of the Aneurysm in the Monitor
After completing the procedure, the catheters and sheath were removed, and a superficial pressure dressing using a radial pressure band was immediately applied to the puncture site, without further manual hemostasis. Pulsation of the radial and ulnar arteries was re-evaluated after adequate homeostasis. Bed rest was not required following the procedure.

\section{Results}

Although transradial artery neurointerventional approach to this cerebral aneurysm was our first experience, fortunately it was performed with success and the basilar tip aneurysm was treated completely without any complication and also our patient had a good post-operative period.

\section{Discussion}

In this study, we described our first experience of coiling the cerebral aneurysm via right hand transradial artery. Although the transradial approach is used for cerebral diagnostic angiography, its usage for therapeutic purposes is unusual. For our patient, we used transradial approach due to unfavorable vascular anatomy and the aneurysm was treated successfully. Our patient reported a good post-operative period.

Samir Sur et al. described the transradial approach for mechanical thrombectomy in anterior circulation largevessel occlusion [13]. In 1989, Lucien Campeau introduced the transradial approach for coronary angiography

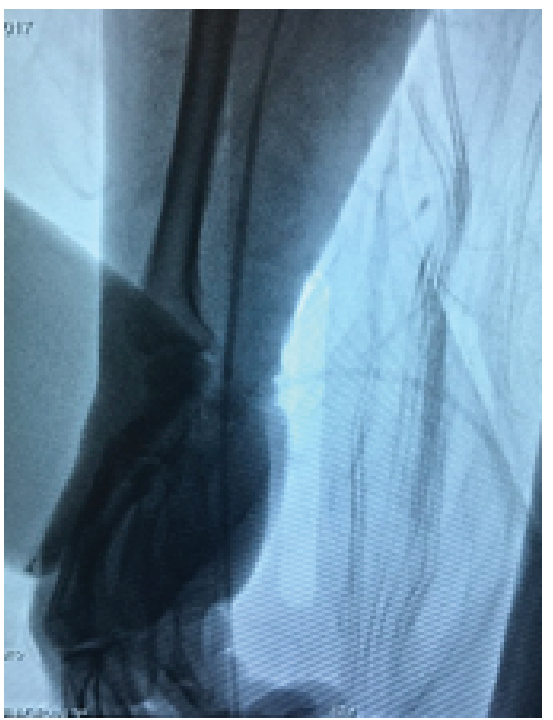

Figure 2. Guiding Catheter through Radial Artery 


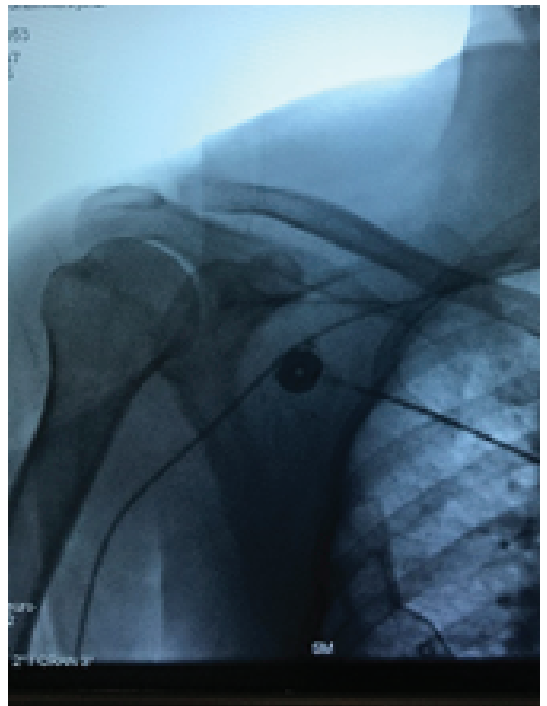

INS

Figure 3. Guiding Catheter through Radial Artery

for the first time [14]. The success rate of transradial cerebral angiography is reportedly $92.7-99 \%[5,9,11,12,15]$.

Mendiz OA et al., described their initial experience with transradial access for carotid artery stenting [16]. It has many potentials over the transfemoral approach for cerebral angiography. The radial artery is compressible, therefore the risk of hemorrhage is very low. It has no nearby important vessels or nerves and due to relatively fixed position of the radial artery, risks of injury to these structures are minimal $[17,18]$. Also this approach does not need bed rest, allowing for immediate ambulation $[1,9,19]$. On the other hand, the transradial approach has caused controversies due to its level of success compared to the other method. Besides, according to prior reports extensive atherosclerotic diseases, atypical anatomy of aortic or brachiocephalic vessels and iliofemoral diseases, etc limit the transfemoral approach $[2,8]$ which is likely to cause groin compression and longer bed rest [15, 20-22].

Some researchers have concluded that radial artery is vasoreactive which makes the first successful puncture important. Post-surgical recommendations include taking spasmolytic medication namely isosorbide dinitrate. Importantly, 2 to $10 \%$ of patients may face complications after transradial coronary angiography due to radial artery occlusion so it should be taken seriously [14, 23-26] as prolonged cannulation, the small diameter of the radial artery, the ratio of the radial artery diameter to the sheath outer diameter, and to the anticoagulation used during arterial cannulation may be the potential
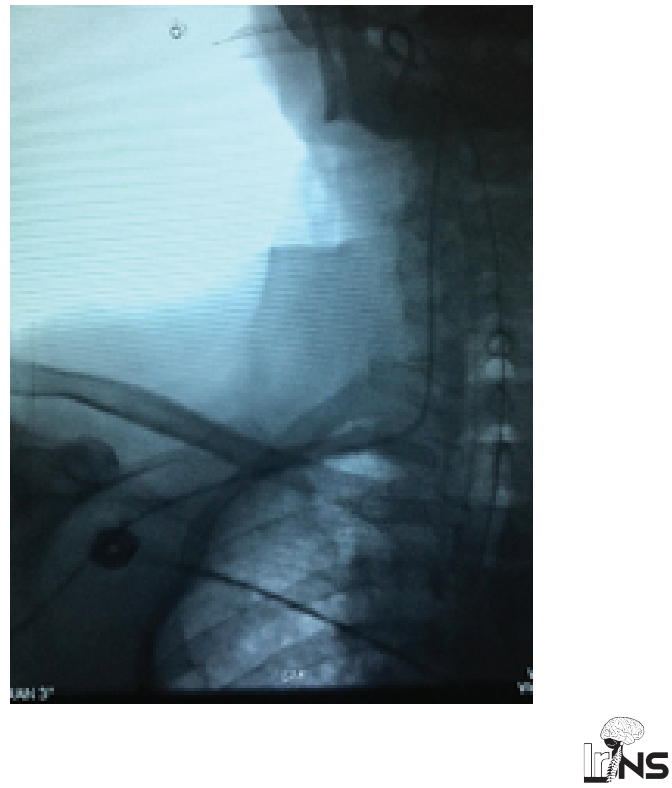

Figure 4. Guiding Catheter through Right Subclavian and Vertebral Artery

causes $[25,27,28]$. In transradial cerebral angiography, if a navigation into the left ICA (difficult to catheterize in patients with high tortuosity) or left VA (difficult to capture) is required, a right transradial procedure may be more challenging. In our case we selected right vertebral artery instead of the left one due to the reasons mentioned above.

\section{Conclusion}

The results of our study suggested that a transradial approach for cerebral angiography and neurointervention was a suitable way, especially for patients with anatomically tortuous vessels as an alternative route. It seems that this route is safe and can be considered as a routine practice in cerebral angiography and neurointervention. Yet, we believe that more studies should be carried out to confirm this finding.

\section{Acknowledgments}

This research did not receive any specific grant from funding agencies in the public, commercial, or not-forprofit sectors.

\section{Conflict of Interest}

The authors declare that they have no conflict of interest. Authors' Contribution is as follows: Conception and Design: Both authors; Data Collection: Both authors; Drafting the Article: Both authors; Critically Revising the Article: Both authors; Reviewing Submitted Version of 
Manuscript: Both authors; and Approving the Final Version of the Manuscript: Both authors.

\section{References}

[1] Agostoni P, Biondi-Zoccai GGL, De Benedictis ML, Rigattieri S, Turri M, Anselmi M, et al. Radial versus femoral approach for percutaneous coronary diagnostic and interventional procedures. Journal of the American College of Cardiology. 2004; 44(2):349-56. doi: 10.1016/j.jacc.2004.04.034

[2] Bendok BR, Przybylo JH, Parkinson R, Hu Y, Awad IA Batjer HH. Neuroendovascular interventions for intracranial posterior circulation disease via the transradial approach : technical case report. Neurosurgery. 2005; 56(3):E626-E626. doi: 10.1227/01.neu.0000154820.28342.38

[3] Hildick-Smith DJ., Lowe MD, Walsh JT, Ludman PF, Stephens NG, Schofield PM, et al. Coronary angiography from the radial artery - experience, complications and limitations. International Journal of Cardiology. 1998; 64(3):231-9. doi 10.1016/s0167-5273(98)00074-6

[4] Kiemeneij F, Laarman GJ, Odekerken D, Slagboom T, van der Wieken R. A randomized comparison of percutaneous transluminal coronary angioplasty by the radial, brachial and femoral approaches: The access study. Journal of the American College of Cardiology. 1997; 29(6):1269-75. doi: 10.1016/ s0735-1097(97)00064-8

[5] Kim JH, Park YS, Chung CG, Park KS, Chung DJ, Kim HJ. Feasibility and Utility of Transradial Cerebral Angiograpy: Experience during the Learning Period. Korean Journal of Radiology. 2006; 7(1):7. doi: 10.3348/kjr.2006.7.1.7

[6] Lotan C, Hasin Y, Mosseri M, Rozenman Y, Admon D, Nassar $\mathrm{H}$, et al. Transradial approach for coronary angiography and angioplasty. The American Journal of Cardiology. 1995; 76(3):164-7. doi: 10.1016/s0002-9149(99)80050-2

[7] Ludman PF, Stephens NG, Harcombe A, Lowe MD, Shapiro LM, Schofield PM, et al. Radial versus femoral approach for diagnostic coronary angiography in stable angina pectoris. The American Journal of Cardiology. 1997; 79(9):1239-41. doi: 10.1016/s0002-9149(97)00089-1.

[8] Fessler RD, Wakhloo AK, Lanzino G, Guterman LR, Hopkins LN. Transradial approach for vertebral artery stenting: Technical case report. Neurosurgery. 2000; 46(6):1524-8. doi 10.1097/00006123-200006000-00044

[9] Iwasaki S, Yokoyama K, Takayama K, Ueda K, Sueyosi S, Nagasawa $\mathrm{M}$, et al. The transradial approach for selective carotid and vertebral angiography. Acta Radiologica. 2002; 43(6):549-55. doi: 10.1034/j.1600-0455.2002.430601.x

[10] Levy EI, Boulos AS, Fessler RD, Bendok BR, Ringer AJ Kim SH, et al. Transradial Cerebral Angiography: An Alternative Route. Neurosurgery. 2002; 51(2):335-42. doi: 10.1097/00006123-200208000-00007

[11] Nohara AM, Kallmes DF. Transradial cerebral angiography: Technique and outcomes. American Journal of Neuroradiology. 2003; 24(6):1247-50. PMID: 12812964
[12] Wu CJ, Hung WC, Chen SM, Yang CH, Chen CJ, Cheng $\mathrm{CI}$, et al. Feasibility and safety of transradial artery approach for selective cerebral angiography. Catheterization and Cardiovascular Interventions. 2005; 66(1):21-6. doi: 10.1002/ ccd.20396

[13] Sur S, Snelling B, Khandelwal P, Caplan JM, Peterson EC, Starke RM, et al. Transradial approach for mechanical thrombectomy in anterior circulation large-vessel occlusion. Neurosurgical Focus. 2017; 42(4):E13. doi: 10.3171/2017.1.focus16525

[14] Campeau L. Percutaneous radial artery approach for coronary angiography. Catheterization and Cardiovascular Diagnosis. 1989; 16(1):3-7. doi: 10.1002/ccd.1810160103

[15] Matsumoto Y, Hongo K, Toriyama T, Nagashima H, Kobayashi S. Transradial approach for diagnostic selective cerebral angiography: Results of a consecutive series of 166 cases. American Journal of Neuroradiology. 2001; 22(4):704-8. PMID: 11290482

[16] Mendiz OA, Sampaolesi AH, Londero HF, Fava CM, Lev GA, Valdivieso LR. Initial Experience With Transradial Access for Carotid Artery Stenting. Vascular and Endovascular Surgery. 2011; 45(6):499-503. doi: 10.1177/1538574411405547

[17] Esente P, Giambartolomei A, Simons AJ, Levy C, Caputo RP. Overcoming vascular anatomic challenges to cardiac catheterization by the radial artery approach: Specific techniques to improve success. Catheterization and Cardiovascular Interventions. 2002; 56(2):207-11. doi: 10.1002/ccd.10233

[18] Valsecchi O, Vassileva A, Musumeci G, Rossini R, Tespili M, Guagliumi G, et al. Failure of transradial approach during coronary interventions: Anatomic considerations. Catheterization and Cardiovascular Interventions. 2006; 67(6):870-8 doi: 10.1002/ccd.20732

[19] Benit E, Vranckx P, Jaspers L, Jackmaert R, Poelmans C, Coninx R. Frequency of a positive modified Allen's test in 1,000 consecutive patients undergoing cardiac catheterization. Catheterization and Cardiovascular Diagnosis. 1996; 38(4):352-54.

[20] Lee DH, Ahn JH, Jeong SS, Eo KS, Park MS. Routine transradial access for conventional cerebral angiography: A single operator's experience of its feasibility and safety. The British Journal of Radiology. 2004; 77(922):831-38. doi: 10.1259/ bjr/89933527

[21] Park SH, Park JC, Hwang JH, Hwang SK, Hamm IS. Role of Three-dimensional computed tomography angiography in the follow-up of patients with aneurysm clips. Journal of Korean Neurosurgical Society. 2006; 39:427-31.

[22] Ricci MA, Trevisani GT, Pilcher DB. Vascular complications of cardiac catheterization. The American Journal of Surgery. 1994; 167(4):375-8. doi: 10.1016/0002-9610(94)90119-8

[23] Kiemeneij F, Laarman GJ, de Melker E. Transradial artery coronary angioplasty. American Heart Journal. 1995 129(1):1-7. doi: 10.1016/0002-8703(95)90034-9

[24] Louvard Y, Krol M, Pezzano M, Sheers L, Piechaud JF, Marien $\mathrm{C}$, et al. Feasibility of routine transradial coronary angiography: A single operator's experience. Journal of Invasive Cardiology. 11(9):543-8. PMID: 10745593

[25] Saito S, Miyake S, Hosokawa G, Tanaka S, Kawamitsu $\mathrm{K}$, Kaneda $\mathrm{H}$, et al. Transradial coronary intervention in 
Japanese patients. Catheterization and Cardiovascular Interventions. 1999; 46(1):37-41. doi: 10.1002/(sici)1522726x(199901)46:1<37::aid-ccd10>3.3.co;2-p

[26] Sakai H, Ikeda S, Harada T, Yonashiro S, Ozumi K, Ohe $\mathrm{H}$, et al. Limitations of successive transradial approach in the same arm: The Japanese experience. Catheterization and Cardiovascular Interventions. 2001; 54(2):204-8. doi: 10.1002/ ccd. 1268

[27] Saito S, Ikei H, Hosokawa G, Tanaka S. Influence of the ratio between radial artery inner diameter and sheath outer diameter on radial artery flow after transradial coronary intervention. Catheterization and Cardiovascular Interventions. 1999; 46(2):173-78. doi: 10.1002/(sici)1522726x(199902)46:2<173::aid-ccd12>3.0.co;2-4

[28] Yokoyama N, Takeshita S, Ochiai M, Koyama Y, Hoshino $\mathrm{S}$, Isshiki $\mathrm{T}$, et al. Anatomic variations of the radial artery in patients undergoing transradial coronary intervention. Catheterization and Cardiovascular Interventions. 2000; 49(4):35762. doi: 10.1002/(sici)1522-726x(200004)49:4<357::aidccd1>3.0.co;2-z 